\title{
DUALIDADE EDUCACIONAL E FORMAÇÃO POLITÉCNICA: APROXIMAÇÕES AO DEBATE TEÓRICO
}

\author{
Juliane dos Santos*, Lucas Antonio Feitosa de Jesus, Luiz Gustavo da Silva Bispo Andrade, \\ Maria Silene da Silva \\ *E-mail: julianesantos.ufs@gmail.com \\ Instituto Federal de Educação, Ciência e Tecnologia de Sergipe \\ DOI: $10.15628 /$ rbept.2020.9355
}

Artigo submetido em jan/2020 e aceito em mar/2020

\begin{abstract}
RESUMO
O presente artigo discute as manifestações históricas da dualidade educacional no sistema capitalista de produção e apresenta algumas considerações acerca da educação politécnica enquanto concepção marxista que objetiva contrapor o dualismo escolar, por meio da promoção uma formação humana integral. $\mathrm{O}$ estudo visa contribuir para o debate pontuando algumas problemáticas que norteiam a discussão sobre as possibilidades de implementação da educação politécnica no sistema de ensino. As reflexões foram realizadas a partir de uma revisão bibliográfica, baseada em autores como Ramos (2017); Grabowski e Kuenzer (2016); Moura, Lima Filho e Silva (2015); Arruda (2002); Saviani (2007); Frigotto (2009); Marx (1996); Gramsci (2000); outros. Conclui-se que é necessário pautar a questão na sociedade vigente, começando a debater a oferta de uma educação que tem como pressuposto a superação da dicotomia teoria e prática, trabalho manual e trabalho intelectual, formação profissional e formação propedêutica. Em que pesem as contradições do sistema educacional na sociedade capitalista, a discussão realizada sinaliza para o posicionamento dos sujeitos educativos na defesa de processos formativos que promovam a emancipação humana.
\end{abstract}

Palavras-Chave: Trabalho. Educação profissional. Formação humana.

\section{EDUCATIONAL DUALITY AND POLYTECHNIC FORMATION: APPROXIMATIONS TO THEORETICAL DEBATE}

\begin{abstract}
The present article discusses the historical manifestations of educational duality in the capitalist system of production and presents some considerations about polytechnic education as a Marxist conception that aims to counter school dualism by promoting an integral human formation. The study aims to contribute to the debate by highlighting some issues that guide the discussion about the possibilities of implementing polytechnic education in education systems. The reflections were based on a bibliographical review, based on authors such as Ramos (2017); Grabowski e Kuenzer (2016); Moura, Lima Filho e Silva (2015); Arruda (2002); Saviani (2007); Frigotto (2009); Marx (1996); Gramsci (2000); others. We conclude that it is necessary to orient the question in the current society, beginning to discuss the offer of an education that has as a presupposition the overcoming of the dichotomy theory and practice, manual work and intellectual work, professional training and preparatory training. In spite of the contradictions of the educational system in capitalist society, the discussion held signals the positioning of educational subjects in the defense of formative processes that promote human emancipation.
\end{abstract}

Keywords: Work. Professional education. Human formation. 


\section{INTRODUÇÃO}

Sabe-se que as relações sociais são determinadas pelas relações de produção, sendo que as últimas direcionam as formas como os indivíduos se relacionam, bem como conduz a estruturação da sociedade em classes. Nesse processo, por intermédio do trabalho, o homem transforma a natureza e se autotransforma, num processo de objetivação-exteriorização (LESSA, 2015).

O presente artigo realizou uma síntese das temáticas que perpassam a defesa de uma educação politécnica para a formação humana integral do indivíduo, tendo como objeto de estudo a dualidade educacional, ainda presente no sistema de ensino brasileiro, nos moldes do capitalismo contemporâneo.

A discussão é fundamentada numa pesquisa bibliográfica, a partir da compreensão do trabalho como princípio educativo, apoiando-se em autores como Ramos (2017); Grabowski e Kuenzer (2016); Moura, Lima Filho e Silva (2015); Arruda (2002); Saviani (2007); Frigotto (2009); Marx (1996); Gramsci (2000); outros. Com base no exposto, foram elencadas algumas considerações acerca da defesa de uma educação politécnica a ser implantada no sistema de ensino - visualizando o ensino médio e a educação profissional e tecnológica de nível médio, de forma integrada, como travessia para essa realização -, conduzida pelos argumentos que contradizem as propostas do sistema capitalista de produção.

É importante esclarecer que não se pretende, neste trabalho, entrar numa discussão sobre os aparatos legais que regulamentam as estruturas da educação nos dias atuais, pois caberia uma análise mais detalhada e rigorosa das formas de como se caminha os sistemas de ensino. O objetivo é trazer elementos teóricos para a discussão sobre a dualidade educacional que permeia as relações educativas, valendo-se da educação enquanto alternativa de contraposição a esse dualismo escolar, por meio da elucidação de propostas para a efetivação da formação omnilateral no espaço educativo.

Assim, apoiando-se nos referenciais teóricos, a proposta da reflexão é partir da educação sistemática ofertada à classe trabalhadora versus a educação direcionada às elites dirigentes, adotando como posicionamento de antítese à forma como essa educação está sendo ofertada. Além disso, aponta-se para a necessidade de se construir, ainda nas contradições do sistema capitalista de produção, caminhos para uma educação que promova o indivíduo em suas múltiplas capacidades, na expectativa de sua emancipação enquanto cidadão ativo, para que tenham condições de contribuir para a transformação social.

\section{METODOLOGIA}

Pautado numa pesquisa bibliográfica, o artigo em questão fez parte do programa de atividades da disciplina Bases Conceituais da Educação 
Profissional e Tecnológica, do Mestrado Profissional em Educação Profissional e Tecnológica (PROFEPT), do Instituto Federal de Educação, Ciência e Tecnologia de Sergipe (IFS). Por esse motivo, fundamentou-se metodologicamente a partir das discussões em sala de aula, estudos, resenhas e debates entre os autores, fruto do desenvolvimento do conteúdo programático e apreciação pela temática.

Para esse artigo, foi escrito um texto a respeito de alguns conceitos relacionados a Educação Profissional e Tecnológica, levando o leitor a uma reflexão sobre a educação dual e a formação politécnica. Embasado em estudiosos da Educação Profissional e Tecnológica, contou inicialmente com a bibliografia sugerida na ementa da disciplina em questão, o que não impediu de, no decorrer e após o curso da disciplina buscar referências complementares, amadurecendo as discussões em sala de aula e a partir disso aprimorar a escrita. De acordo com Galvão (2010) o levantamento bibliográfico nos potencializa intelectualmente, e a partir da produção coletiva permite ir além ao que tange a temática pesquisada, munindo-nos de condições cognitivas mais apropriadas.

\section{RESULTADOS E DISCUSSÕES}

O presente artigo aborda alguns elementos teóricos para a discussão sobre a dualidade educacional que permeia as relações educativas, valendose da educação enquanto alternativa de contraposição a esse dualismo escolar, por meio da elucidação de propostas para a efetivação da formação omnilateral no espaço educativo.

Num primeiro momento tem-se a discussão sobre a ontológica e histórica relação entre trabalho e educação. O segundo momento discute a lógica de dualidade educacional no sistema capitalista de produção. Por fim, têm-se algumas considerações sobre a defesa de uma educação politécnica, de uma formação humana integral, omnilateral.

\subsection{A relação Trabalho e Educação: algumas aproximações}

Inicialmente, é importante salientar os extratos de Saviani (2007). Em seu estudo, o autor destaca que "[...] constatado o estrito vínculo ontológicohistórico próprio da relação entre trabalho e educação, impõe-se reconhecer e buscar compreender como se produziu, historicamente, a separação entre trabalho e educação" (SAVIANI, 2007, p. 152).

Percebe-se que a relação do trabalho com a educação é indissociável, porém é preciso compreender os conflitos ideológicos que impuseram na história da educação e que provocam reflexões na sociedade contemporânea. A ontológica e histórica relação ocasionou na proposta de práticas educativas que se utilizam do trabalho enquanto princípio educativo, 
conforme considera Gramsci, ao dizer que é a partir do trabalho que o homem transforma a natureza e se socializa.

Nesse viés, o autor defende uma escola de formação unitária e humanística, que desenvolva capacidades a partir da associação entre o trabalho manual e o intelectual, articulando o "operar manualmente" e o "operar intelectualmente" no processo de formação integral.

[...] Não se pode separar o homo faber do homo sapiens. Em suma, todo homem, fora de sua profissão, desenvolve uma atividade intelectual qualquer, ou seja, é um "filósofo", um artista, um homem de gosto. (GRAMSCI, 2000, p. 53 apud MOURA; LIMA FILHO; SILVA, 2015, p. 1063).

A partir do exposto e em concordância com Barato (2008, p. 6), "[...] ignorar a inteligência do trabalhador manual faz parte de um jogo que desqualifica aqueles cujas funções foram ou são muito simplificadas." Para melhor explicitar essa desqualificação do trabalhador braçal, esse mesmo autor aborda, ainda nesta obra ${ }^{1}$, a conhecida história de Taylor e Schmidt, esse último escolhido pelo primeiro para ilustrar a antiga e atual relação de submissão do trabalho manual ao trabalho científico dentro de diversas fábricas de produção/empresas.

[...] Na narrativa de seu encontro com Schmidt, Taylor, segundo Mike Rose ${ }^{2}$, caracteriza aquele trabalhador como alguém incapaz até de realizar boa parte de tarefas não especializadas. A história toda, contada para justificar um controle radical das atividades de produção, reflete certamente muitos preconceitos. Schmidt, na época em que foi instruído por Taylor, estava construindo sua própria casa. Todas as demandas de planejamento para poupar recursos e aplicá-los na compra de materiais, assim como os diversos saberes necessários para executar a obra, não eram banais. Exigiam inteligência. Taylor era incapaz de enxergar isso. Convinha rotular o trabalhador braçal como alguém desprovido de saberes. (BARATO, 2008, p. 6).

O homem é um ser dotado de inteligência racional, quanto a isso, não há dúvidas. Contudo, Taylor, no exemplo acima era incapaz de reconhecer e assumir o potencial do trabalhador braçal, um dos princípios do ideal taylorista, pode-se dizer. Contrapondo as ideias tayloristas e em concordância com a defesa de Barato (2008) acerca da inteligência do ser humano, seja ele trabalhador braçal ou não, Saviani (2007, p. 154) reconhece que

\footnotetext{
${ }^{1}$ BARATO, Jarbas Novelino. Conhecimento, Trabalho e Obra: uma proposta metodológica para a educação profissional. B. Téc. Senac: a R. Educ. Prof., Rio de Janeiro, v. 34, n. 32, set./ dez. 2008.

${ }^{2}$ ROSE, Mike. O saber no trabalho: valorização da inteligência do trabalhador. São Paulo: Ed. Senac São Paulo, 2007.
} 
[...] o ato de agir sobre a natureza transformando-a em função das necessidades humanas é o que conhecemos com o nome de trabalho. Podemos, pois, dizer que a essência do homem é o trabalho [...] A essência humana é produzida pelos próprios homens. O que o homem é, é-o pelo trabalho. A essência do homem é um feito humano. É um trabalho que se desenvolve, se aprofunda e se complexifica ao longo do tempo: é um processo histórico. [...] o homem não nasce homem. Ele forma-se homem. Ele não nasce sabendo produzir-se como homem. Ele necessita aprender a ser homem, precisa aprender a produzir sua própria existência. Portanto, a produção do homem é, ao mesmo tempo, a formação do homem, isto é, um processo educativo. A origem da educação coincide, então, com a origem do homem mesmo.

Ainda segundo o autor, trabalhar é agir sobre a natureza e transformála, não é outra coisa senão isto (SAVIANI, 1989). E para fortalecer a discussão, Karl Marx pontua como se manifesta a categoria trabalho no sistema capitalista de produção. Nesse sistema, o capital exerce uma dupla dominação sobre o trabalho, por meio do controle no processo de produção e da apropriação dos meios de produção, que resulta - dentro das artimanhas do capital - na força de trabalho enquanto mercadoria e no trabalho alienado. (MARX, 1996).

Segundo Arruda (2002), apoiado nos escritos de Marx, o trabalho é atividade produtiva concatenada com a teoria para compreensão da dinâmica da realidade social e dos elementos essenciais às ciências. É um trabalho que exclui qualquer oposição entre cultura e profissão.

[...] Marx fala na formação intelectual e espiritual associada à formação técnica e científica. Daí a sua proposta de formação do 'homem omnilateral'. Seu aceno com o 'reino da liberdade' abre um horizonte ainda mais amplo para o desenvolvimento das relações dos seres humanos entre si e com a natureza. (ARRUDA, 2002, p. 68).

É indispensável o questionamento acerca do reducionismo e do utilitarismo do trabalho na produção material da subsistência. Do mesmo modo, é importante questionar o caráter explorador do trabalho na sociedade capitalista, indagando sobre as formas capitalistas de organização, a divisão social e técnica do trabalho, a exploração e alienação do trabalho produtivo, do trabalho em si, e da relação do homem com a natureza.

Eminentemente, a relação homem-natureza nas sociedades que antecedem o capitalismo era baseada nas relações de trocas, não na disputa pelos recursos naturais. $O$ trabalho não era realizado, necessariamente, com vistas à obtenção do lucro, mas, precisamente voltado à reprodução dos 
homens em sua comunidade/sociedade. Um exemplo disso é o modo feudal de produção e, tão logo esse modo de produção "entra em crise", se dá o avanço de uma nova forma de sociabilidade, pautada na exploração, na destruição da natureza e no acelerado ritmo de produção de mercadorias, das quais, o homem, na sua relação com outros homens, passa a se tornar, também, uma mercadoria (MARX, 1996).

A produção de mercadorias na sociedade capitalista não está voltada essencialmente aos aspectos relacionados ao trabalhador e a sua família, mas à reprodução e manutenção do capital, que visa apenas a produção da mais-valia. O valor de uso da mercadoria fica obscurecido, escondido, em relação ao valor de troca. Portanto, o fetiche da mercadoria é oposto ao valor de uso delas, no qual o homem consome diversos produtos sem, contudo, levar em consideração as relações sociais existentes em sua produção (MARX, 1996).

A partir do exposto, nota-se que as coisas materiais se transformam e se valorizam mais que as relações subjetivas. Esse processo manipulador é introduzido nas relações cotidianas sem que os indivíduos percebam. Em suma, os indivíduos, no sistema capitalista, são aquilo que eles possuem, o mundo das coisas acaba por dominar o mundo dos homens, todos os valores tornam-se objetos das relações mercantis, onde tudo se baseia na troca de mercadorias. Marx denomina essas relações, ora estabelecidas pelo capital, de fetichismo da mercadoria.

[...] Nessa vida de operário, nós somos a nossa força de trabalho e percebemos que ela vale estritamente aquilo que $o$ capitalista crê que ela pode produzir de ganho para ele. Como ela é uma mercadoria, nós também nos sentimos - e, de fato, somos - reduzidos à mercadoria. (ARRUDA, 2002, p. $63)$.

As transformações no mundo do trabalho afetam, obviamente, a classe trabalhadora a qual apresenta, nos dias atuais, uma nova forma de ser. A classe trabalhadora hodierna inclui a totalidade das pessoas que vendem a sua força de trabalho, como os trabalhadores improdutivos (bancários, comerciantes), os trabalhadores assalariados, e também os desempregados que, intencionalmente, são vítimas da lógica destrutiva do capital. (ANTUNES, 1999).

Antunes (1999), afirma que a estrutura societal contemporânea vem sendo acometida de profundas transformações, subjetivas e objetivas, nas quais se tem acarretado significativas mutações no mundo do trabalho. $O$ desemprego estrutural, a precarização do trabalho, a degradação na relação metabólica entre homem e natureza, a supervalorização do capital, a exploração exacerbada da classe trabalhadora são algumas das expressões desse processo.

Não obstante, é importante que, dentro das contradições do sistema capitalista de produção, se propague a luta contra-hegemônica. "[...] A disputa 
das concepções, teorias e práticas educativas e de ciência e tecnologia situam-se nesse terreno" (FRIGOTTO, 2009, p. 185).

Diante do contexto implementado pelo sistema capitalista e das relações estabelecidas, torna-se essencial refletir sobre o caráter dualista da educação no modo de produção capitalista, elucidando as influencias que a educação exerce para essa sociedade de classes.

\subsection{A lógica da dualidade estrutural no sistema capitalista de produção}

Importa esclarecer que a lógica da dualidade educacional não é uma invenção perversa do capitalismo (RODRIGUES, 2005), entretanto, compreender a educação no sistema capitalista de produção implica captar a lógica da dualidade estrutural, expressa com maior relevância no ensino médio, principalmente nas relações estabelecidas atualmente entre esta etapa de formação e a educação profissional.

Entre as categorias que permitem compreender a educação no modo de produção capitalista está a dualidade estrutural; contudo, é a partir do ensino médio, e em especial na educação profissional, que essa categoria apresenta maior poder explicativo. (KUENZER; GRABOWSK, 2016, p. 24).

Historicamente, a educação brasileira apresenta marcas de uma dualidade estrutural. Isso porque, durante séculos, a educação no contexto da escola primitiva era algo restrito a uma parcela mínima da população. A educação que é ofertada atualmente para a classe trabalhadora ainda se difere significativamente da que é ofertada para as classes dirigentes, ou seja, de um lado prioriza-se a oferta do ensino profissionalizante (para fins instrumentais) para os filhos dos trabalhadores, e de outro, o ensino propedêutico (para fins intelectuais) para os filhos das classes dominantes.

Nas palavras de Saviani (2007, p. 159),

[...] a proposta dualista de escolas profissionais para os trabalhadores e "escolas de ciências e humanidades" para os futuros dirigentes; e a proposta de escola única diferenciada, que efetuava internamente a distribuição dos educandos segundo as funções sociais para as quais se os destinavam em consonância com as características que geralmente decorriam de sua origem social. (SAVIANI, 2007, p. 159).

Ao tratar da concepção de politecnia, Saviani (1989) afirma que esta se encaminha na contramão da dualidade educacional, ora, na direção da sua superação. Ela aguça o restabelecimento da união entre trabalho e educação, mediante a concepção do trabalho como princípio educativo. A ideia de formação politécnica não implica em apenas garantir o desenvolvimento de uma habilidade específica, mas, garantir também os fundamentos que dão base para atuação em qualquer outra área/função específica. Queira dizer: 
[...] qualquer que seja a função específica que o aluno seja chamado a exercer, ele tem os fundamentos, os princípios, os pressupostos para poder exercê-la com uma compreensão plena do lugar que ele ocupa na totalidade do social. (SAVIANI, 1989, p. 40).

Todavia, o quadro da educação brasileira para a classe trabalhadora mais desmorona do que ascende. Nos anos de 1960, com a Lei no 4.024/1961 - Lei de Diretrizes e Bases da Educação Nacional (LBD) -, os estudantes tanto do ensino médio (colegial) quanto do ensino profissional poderiam ingressar de imediato no ensino superior, formalmente falando, pois, isso não colocava um fim na dualidade de ensino em virtude da forma de acesso ao ensino superior privilegiar as elites, as quais tinham acesso aos conteúdos exigidos (sejam esses das ciências, artes, literatura e letras) nos processos de seleção e reduzidos - quase inexistentes - nos cursos profissionalizantes. (MOURA, 2010).

Com a promulgação da Constituição Federal de 1988, ocorre no Congresso Nacional a aprovação da Lei no 9.394 de 1996. Nesta, a educação brasileira "regular" é estruturada em níveis de educação, compreendida por educação básica e superior, excluindo-se a educação profissional. A promulgação do Decreto $\mathrm{n}^{\circ} 2.208$ no ano seguinte, 1997, reforça essa dualidade, conforme trecho do artigo $5^{\circ}$ do referido decreto, o qual afirmava que "[...] a educação profissional de nível técnico terá organização curricular própria e independente do ensino médio".

A partir da separação entre o ensino médio e os cursos técnicos, o primeiro retoma seu sentido propedêutico e o segundo é ofertado de forma subsequente e concomitante. Em contrapartida a essa dualidade, 0 Documento Base da Educação Profissional Técnica de Nível Médio Integrada ao Ensino Médio, defende

[...] Uma formação voltada para a superação da dualidade estrutural entre cultura geral e cultura técnica ou formação instrumental (para os filhos da classe operária) versus formação acadêmica (para os filhos das classes média-alta e alta). [...] Uma formação voltada, tanto em sua vertente dirigida aos adolescentes como ao público da EJA, à formação de cidadãos capazes de compreender a realidade social, econômica, política, cultural e do mundo do trabalho para nela inserir-se e atuar de forma ética e competente, técnica e politicamente, visando contribuir para a transformação da sociedade em função dos interesses sociais e coletivos. (BRASIL, 2007, p. 25, grifo nosso).

Ainda no governo de Luiz Inácio Lula da Silva, intensificam-se as discussões sobre o Decreto 2.208/1997, o que retoma a debate acerca da educação politécnica, "[...] compreendendo-a como uma educação unitária e universal destinada à superação da dualidade entre cultura geral e cultura 
técnica e direcionada para não se voltar, no entanto, para uma formação profissional stricto sensu" (MOURA, 2010, p. 73).

Nasce, a partir dessas discussões, o Decreto nํ⒌154/2004, que traz de volta a possibilidade de integração da educação profissional técnica de nível médio com o ensino médio, apontando para a construção de uma educação politécnica, apesar de manter as ofertas dos cursos técnicos subsequentes e concomitantes, trazidos pelo Decreto no 2.208/1997, revogado a partir do nascimento deste outro.

Nos dias atuais, a mais nova contrarreforma no sistema educacional de ensino expressa-se mediante a aprovação da Lei $n$ ํ 13.415/2017, o que agride mais uma vez a classe trabalhadora no sentido de garantir a esse público uma educação básica pública e de qualidade. Tendo em vista que essa lei se é contrária à proposta de ensino médio integrado.

Logo, a história do sistema educacional brasileiro é, segundo Ramos (2017, p. 24-25),

[...] atravessada por importantes reformas educacionais, dentre as quais, citamos a de Francisco Campos, que possibilitou a organização de seus sistemas pelos estados da federação; a de Gustavo Capanema, que buscou dar organicidade as formas escolares, em especial, com as chamadas leis orgânicas da educação; a reforma do governo civil-militar, o qual fez as reformas do ensino universitário e secundário, este último mediante a Lei oㅡ 5.692/71, tornando formação profissional compulsória no $2^{\circ}$ grau, posteriormente, revogada pela Lei no 7.044/82; a de Fernando Henrique Cardozo, depois da aprovação da Lei no 9.393/1996, implementada pelo Decreto no 2.208/1997, que separou a formação profissional do Ensino Médio, e a própria reforma deste último, por meio de Diretrizes Curriculares Nacionais baseadas em competências; e a reforma do governo Luís Inácio Lula da Silva, que revogou este Decreto por meio de outro, o Decreto no 5.154/2004. E, a partir desse momento, quando se retoma a discussão da formação integrada inspirada pela concepção de educação politécnica debatida na década de 1980. Finalmente, vivemos, hoje, uma contrarreforma implementada pela Lei no $13.415 / 2017$, a qual recupera as piores medidas de reformas anteriores.

Sendo assim, essas contrarreformas, em sua maioria, retomam a dualidade sempre presente na educação brasileira, esta última, ainda pior, conforme salienta Ramos (2017) no texto acima. Confirma-se, portanto, a reprodução da dicotomia entre trabalho manual e intelectual. E na sociedade vigente, se intensifica tal dualidade, porém, com uma nova roupagem, conforme indica Kuenzer e Grabowsk (2016, p. 25),

O novo discurso do capital sobre a educação aponta para a necessidade da formação de profissionais flexíveis; se 0 trabalhador 
transitará ao longo de sua trajetória laboral por inúmeras ocupações e oportunidades de educação profissional, não há razão para investir em formação profissional especializada; a integração entre as trajetórias de escolaridade e laboral será o elo de integração entre teoria e prática, resgatando-se, desta forma, a unidade rompida pela clássica forma de divisão técnica do trabalho, que atribuía a uns o trabalho operacional, simplificado, e a outros o trabalho intelectual, complexo.

Logo, a oferta de educação para a classe trabalhadora, a qual tem como referência o ensino médio, acontece a partir da oferta de cursos precarizados, voltados para a produção de mão de obra para o mercado de trabalho, ou seja, visando a formação de força de trabalho para o atendimento das necessidades imediatas do capital.

Todavia, apesar dessa crescente polarização da educação do trabalhador à qualificação para o atendimento as necessidades imediatas do mercado de trabalho, vale-se ressaltar que houve, de certo modo, uma ampliação da oferta da educação - ainda que predominantemente básica para a classe trabalhadora.

A estratégia através da qual o conhecimento é disponibilizado/negado segundo as necessidades desiguais e diferenciadas dos processos de trabalho integrados é o que temos chamado de inclusão excludente na ponta da escola. Ao invés da explícita negação das oportunidades de acesso à educação continuada e de qualidade, há uma aparente disponibilização das oportunidades educacionais, através de múltiplas modalidades e diferentes naturezas, que se caracterizam por seu caráter desigual e na maioria das vezes meramente certificatório, que não asseguram domínio de conhecimentos necessários ao desenvolvimento de competências cognitivas complexas vinculadas à autonomia intelectual, ética e estética. (KUENZER e GRABOWSK, 2016, p. 28).

É perceptível que a lógica desse projeto societário de educação para a manutenção do capital ocasiona na dualidade estrutural, concebida de forma desigual e diferenciada, de modo a assegurar uma educação básica precarizada para "classe-que-vive-do-trabalho" e, outra educação, de natureza científica e sócio-histórica, para os que exercerão funções consideradas intelectuais.

Assim, corrobora-se com Saviani (1989, p. 15) quando diz que "O ensino profissional é destinado àqueles que devem executar, enquanto que o ensino científico-intelectual é destinado àqueles que devem conceber e controlar o processo". É importante salientar que as palavras de Saviani (1989) não traduzem suas formas de conceber a educação, mas expõe os objetivos da implementação da educação profissional no Brasil, que são a

\footnotetext{
${ }^{3}$ Totalidade dos assalariados que vivem da venda da força de trabalho. (ANTUNES, 1999).
} 
produção de trabalhadores para o trabalho técnico e manual, para a conformação social e a manutenção da dualidade educacional.

Nesse contexto, destaca-se a educação politécnica ou tecnológica. É o termo criado por Karl Marx como proposta de materializar um projeto de educação de superação da dualidade entre formação profissional e educação propedêutica. Para isso, é necessário que as reflexões apresentadas estejam alicerçadas nas transformações que vêm ocorrendo na sociedade, no mundo do trabalho e, consequentemente, na organização do sistema de ensino.

\subsection{Educação Politécnica: um caminho possível?}

É possível a superação da lógica da dualidade estrutural da educação na sociedade vigente rumo a uma formação humana integral, omnilateral e politécnica? Segundo Saviani (1989, p. 13), "A noção de politecnia se encaminha na direção da superação entre trabalho manual e trabalho intelectual, entre instrução profissional e instrução geral". Desse modo, como desenvolver, no Brasil contemporâneo, uma forma de educação que supere essa dicotomia entre educação profissional e educação propedêutica?

A divisão social e técnica do trabalho, no modo de produção capitalista, constitui-se como estratégia essencial a reprodução das classes sociais. Desse modo, quando se trata da estrutura da educação na sociedade vigente, nota-se claramente que a opção é por um sistema educacional divorciado no que se refere às relações entre trabalho manual e trabalho intelectual, escola e sociedade, formação profissional e propedêutica, teoria e prática, decisão e execução, entre cultura geral e cultura técnica. A regra do capitalismo é manter um modelo de educação funcionalista, unilateral e utilitarista, para atender aos anseios das classes dominantes. (MOURA; LIMA FILHO; SILVA, 2015).

Retornando à indagação inicial, qual seja, como pensar um modelo de escola que esteja voltada para uma formação omnilateral, politécnica e que contemple a classe trabalhadora? A luta de vários estudiosos por uma educação que compreenda a formação humana integral e emancipatória é histórica e tem sido transcorrida por dificuldades, do ponto de vista político e econômico, para sua implementação no contexto educacional.

A formação que articula corpo, mente e técnica, para a classe trabalhadora, tem sido negada, pois a oferta desse tipo de formação é traduzida, historicamente, pelo caráter classista. É necessário, portanto, que - sistema educacional de ensino, em seu currículo básico, tenha como pressuposto o trabalho como princípio educativo do "[...] processo através do qual o homem [se transforma e,] transforma a natureza." (SAVIANI, 1989, p. 11).

Esse mesmo autor pontua, "[...] a noção de politecnia deriva basicamente da problemática do trabalho, parece-me importante considerar que o nosso ponto de referência é a noção do trabalho, o conceito e o fato do trabalho como princípio educativo geral." (SAVIANI, 1989, p. 7). O trabalho como princípio educativo é conduzido pela noção de politecnia, termo que 
tem como fundamento a noção do trabalho, e da efetivação deste como princípio educativo.

Segundo o viés marxista, a educação politécnica ou formação tecnológica é a mais profunda expressão da união entre trabalho e escola, formação intelectual e formação manual, entre cultura geral e cultura técnica. Sendo assim, Saviani (1989, p. 17, grifo original) compreende que

A noção de politecnia diz respeito ao domínio dos fundamentos científicos das diferentes técnicas que caracterizam o processo de trabalho moderno. Diz respeito aos fundamentos das diferentes modalidades de trabalho. Politecnia, nesse sentido, se baseia em determinados princípios, determinados fundamentos e a formação politécnica deve garantir o domínio desses princípios, desses fundamentos.

A educação politécnica, baseada no trabalho como princípio educativo, traz elementos que contrapõem a ideia de que aos trabalhadores devem ser ofertado apenas conhecimentos necessários às atividades laborativas, sem ao menos proporcionar a estes sujeitos um ensino que promova a compreensão dos fundamentos científicos que caracterizam os processos de trabalho.

A oferta dessa educação dualista acaba por fragmentar o processo de construção do saber, condicionando ao trabalhador uma formação profissionalizante utilitarista e unilateral, voltada a execução de atividades meramente operacionais. Desse contexto, resulta-se na dualidade estrutural e educacional, condicionada à diferenciação entre o tipo de educação que é ofertada à elite da formação que é oferecida à classe trabalhadora.

O ensino profissionalizante é destinado àqueles que devem executar, enquanto que o ensino científico-intelectual é destinado àqueles que devem conceber e controlar 0 processo. (...) A idéia de politecnia contrapõe-se à referida concepção. Ela postula que o processo de trabalho desenvolva, numa unidade indissolúvel, os aspectos manuais e intelectuais. Um pressuposto dessa concepção é de que não existe trabalho manual puro, e nem trabalho intelectual puro. Todo trabalho humano envolve a concomitância do exercício dos membros, das mãos, e do exercício mental, intelectual. (SAVIANI, 1989, p. 14-15).

Nessa perspectiva, na concepção da politecnia não existe um trabalho meramente manual ou meramente intelectual, a relação entre ambos é indissolúvel. É o que Araújo e Frigotto (2015) chamam de "atividade teóricoprática" ou, simplesmente, práxis. A apreensão por parte do trabalhador nas funções manuais a serem executadas no processo produtivo, por exemplo, requer que este disponha de um mínimo de conhecimento cognitivo e 
intelectual. Na mesma medida, o trabalho intelectual desenvolve-se através de recursos práticos.

Assim, as reflexões acerca do debate da defesa de uma educação politécnica, baseado na análise dos fundamentos e discussões sobre a noção de politecnia, e da sua relação com a dualidade estrutural da educação, ressalta a importância de compreender que o conceito de politecnia não está associado à multiplicidade de técnicas - como compreende o sentido epistemológico da palavra -, mas, na assimilação teórica e prática do processo produtivo, da organização da sociedade e das relações sociais. (SAVIANI, 1989).

Portanto, uma organização da estrutura curricular que possibilita uma formação humana integral, omnilateral, politécnica, pressupõe que este:

a) conceba o sujeito como ser histórico-social concreto, capaz de transformar a realidade em que vive; b) vise à formação humana como síntese de formação básica e formação para o trabalho; tenha o trabalho como princípio educativo [...]; seja baseado numa epistemologia que considere a unidade de conhecimentos gerais e conhecimentos específicos e numa metodologia que permita a identificação das especificidades desses conhecimentos quanto à sua historicidade, finalidades e potencialidades; e) seja baseado numa pedagogia que vise à construção conjunta de conhecimentos gerais e específicos, no sentido de que os primeiros fundamentam os segundos e esses evidenciam o caráter produtivo concreto dos primeiros; f) seja centrado nos fundamentos das diferentes técnicas que caracterizam o processo de trabalho moderno, tendo como eixos o trabalho, a ciência e a cultura. (RAMOS, 2012, p. 109110).

Em suma, o grande desafio, posto à sociedade contemporânea, é viabilizar tal formação. Fazendo avançar novas perspectivas de pensar o processo de ensino-aprendizagem e "[...] construir determinadas estruturas, porque é a realidade que determina a consciência e não o contrário [...]" (SAVIANI, 1989, p. 31-32).

É preciso entender, também, que o enfrentamento da lógica do mercado, implementada pelo sistema capitalista, exige uma postura crítica e revolucionária, pois,

[...] A ultrapassagem do capitalismo implica enfrentar, no plano da práxis, o pântano contraditório da dialética do velho e de novo. Como ensina Gramsci, velho que não quer morrer e novo que necessita nascer. Ou se começa a luta pela utopia do socialismo e da educação omnilateral, unitária e politécnica no embate contraditório da realidade rebelde historicamente existente ou teremos, como assinala 
Jameson, que esperar deterioração total da terra e da natureza; ou remeter a um imaginário futuro, na análise de Kosik (1969), a superação do sistema capitalista (FRIGOTTO, 2009, p. 185).

Portanto, é necessário se pensar em formas de ultrapassar esta lógica capitalista, construindo embates sólidos para contrapor às formas de produção, e a partir das bases conceituais de educação politécnica e trabalho como princípio educativo, implementar alternativas para a superação da dualidade estrutural e educacional, ainda presentes no contexto educacional.

\section{CONSIDERAÇÕES FINAIS}

A análise realizada evidencia as críticas da profissionalização do trabalhador, propondo como superação a implementação de uma formação humana integral, politécnica, que compreenda o indivíduo em sua capacidade manual e intelectual, o que implica uma indissociabilidade entre educação, trabalho, ciência, tecnologia e cultura.

É preciso construir meios possíveis para a implantação dos ideais da politecnia. A travessia a essa realização é necessária na estrutura de sociedade. É preciso "engendrar o novo no velho", trazendo uma expectativa de avanço rumo à educação politécnica e, assim, resistir às concepções fundamentadas na perspectiva da fragmentação da formação, voltadas majoritariamente para a "pedagogia das competências". Atualmente é enxertada a ideia central de que a educação profissional e propedêutica continue refletindo uma formação voltada precisamente para o atendimento às necessidades imediatas do capital.

Assim, é necessário romper com qualquer possibilidade endógena de educação. A pretensão é avançar em uma perspectiva que promova um olhar para fora, identificando que a educação se relaciona com os contextos histórico-sociais, para a promoção de uma formação integral aos estudantes.

\section{REFERÊNCIAS}

ARAÚJO, Ronaldo Marcos de Lima; FRIGOTTO, Gaudêncio. Práticas pedagógicas e ensino integrado. Revista Educação em Questão, Natal, v. 52, n.38, p. 61-80, maio/ago. 2015.

ANTUNES, Ricardo. Os sentidos do trabalho: ensaio sobre a afirmação e a negação do trabalho. São Paulo: Boitempo Editorial, 1999.

ARRUDA, Miguel González. A articulação trabalho-educação visando uma democracia integra. In: GOMEZ, C. M. et al. Trabalho e conhecimento: dilemas na educação do trabalhador. 4. ed. São Paulo: Cortez, 2002.

BARATO, Jarbas Novelino. Conhecimento, trabalho e obra: uma proposta 
metodológica para a Educação Profissional. B. Téc. Senac: a R. Educ. Prof., v.34, n. 3, set/dez. 2008.

BRASIL. Lei no 9.394, de 20 de dezembro de 1996. Estabelece as diretrizes e bases da educação nacional. D.O.U., Brasília, 1996. Disponível em: http://www.planalto.gov.br/ccivil_03/Leis/ L9394.htm. Acesso em: 26 nov. 2018.

BRASIL. Lei no 13.415, de 16 de fevereiro de 2017. Conversão da Medida Provisória no 746, de 2016. Altera as Leis nos 9.394, de 20 de dezembro de 1996, que estabelece as diretrizes e bases da educação nacional. D.O.U., Brasília, 2017. Disponível em: http://www.planalto.gov.br/ccivil_03/_Ato20152018/2017/Lei/L13415.htm. Acesso em: 21 nov. 2018.

BRASIL. Educação Profissional Técnica de Nível Médio Integrada ao Ensino Médio. Documento Base. D.O.U. Brasília, 2007. Disponível em: http://portal.mec.gov.br/setec. Acesso em: 25 nov. 2018.

BRASIL. Decreto no 2.208, de 17 de abril de 1997. Regulamenta o $\S 2^{\circ}$ do art. 36 e os arts. 39 a 42 da Lei no 9.394, de 20 de dezembro de 1996, que estabelece as diretrizes e bases da educação nacional. D.O.U., Brasília, 1997. Disponível em: www.planalto.gov.br/ccivil_03/decreto/D2208.htm. Acesso em: 20 nov. 2018.

BRASIL. Decreto no 5. 154, de 23 de julho de 2004. Regulamenta o $\S 2^{\circ}$ do art. 36 e os arts. 39 a 41 da Lei no 9.394, de 20 de dezembro de 1996, que estabelece as diretrizes e bases da educação nacional, e dá outras providências. D.O.U., Brasília, 2004. Disponível em: http://www.planalto.gov.br/ccivil_03/_Ato2004-2006/2004/Decreto/D5154.htm. Acesso em: 22 nov. 2018.

DICIONÁRIO DA EDUCAÇÃO PROFISSIONAL E SAÚDE. Disponível em: http://www.sites.epsjv.fiocruz.br/dicionario/verbetes/duaedu.html. Acesso em: 21 out. 2018.

FRIGOTTO, Gaudêncio. A polissemia da categoria trabalho e a batalha das ideias nas sociedades de classe. Revista Brasileira de Educação. V. 14, n. 40, p. 168-194, jan./abr. 2009.

GALVÃO, Maria Cristiane Barbosa. O levantamento bibliográfico e a pesquisa científica. Ribeirão Preto: Universidade de São Paulo, 2010.

GRABOWSKI, Gabriel; KUENZER, Acácia Zeneida. A produção do conhecimento no campo da Educação Profissional no regime de acumulação flexível. Holos, v. 6, p. 22-32, 2016. Disponível em:

http://www2.ifrn.edu.br/ojs/index.php/HOLOS/article/view/4983. Acesso em: 21 out. 2018.

LESSA, Sérgio. Para Compreender a Ontologia de Lukács. 4a ed.; Instituto Lukács. São Paulo, 2015.

MARX, Karl. O Capital. Vol. 1. São Paulo: Editora Nova Cultural Ltda., 1996.

MOURA, Dante Henrique; LIMA FILHO, Domingos Leite; SILVA, Mônica Ribeiro. Politecnia e formação integrada: confrontos conceituais, projetos políticos e contradições históricas da educação brasileira. Revista Brasileira 
de Educação, v. 20, n. 63, p. 1057-1080, 2015. Disponível em:

http://www.scielo.br/pdf/rbedu/v20n63/1413-2478-rbedu-20-63-1057.pdf. Acesso em: 23 nov. 2018.

MOURA, Dante Henrique. Ensino médio e educação profissional: dualidade histórica e possibilidades de integração. In: MOLL, J. et al. Educação profissional e tecnológica no Brasil contemporâneo: desafios, tensões e possibilidades. Porto Alegre: Artmed, 2010.

RAMOS, Marise Nogueira. Ensino médio integrado: lutas históricas e resistências em tempos de regressão. In: ARAÚJO, A.C; SILVA, C.N.N. Ensino médio integrado no Brasil: fundamentos, práticas e desafios (org.). Brasília: Ed. IFB, 2017, p. 20-43.

RAMOS, Marise Nogueira. Possibilidades e desafios na organização do currículo integrado. In: FRIGOTTO, Gaudêncio.; CIAVATTA, Maria.; RAMOS, Marise Nogueira. (Org.). Ensino Médio Integrado: concepção e contradições. 3. ed. São Paulo: Cortez, 2012, p. 107-128.

RODRIGUES, José. Ainda a educação politécnica: o novo decreto da educação profissional e a permanência da dualidade estrutural. Trabalho, Educação e Saúde, 3(2): 259-282, 2005.

SAVIANI, Dermeval. Trabalho e educação: fundamentos ontológicos e históricos. Revista Brasileira de Educação. V. 12, n. 34, p. 152-180, jan./abr. 2007.

SAVIANI, Dermeval. Sobre a concepção de politecnia. Rio de Janeiro: Fiocruz, 1989. 